\title{
ABORDAGEM SOCIOCULTURAL: ALGUMAS VERTENTES E AUTORES
}

\author{
Adriana Ferreira Paes Ribas* \\ Maria Lucia Seidl de Moura\#
}

\begin{abstract}
RESUMO. A necessidade de enfocar aspectos socioculturais nas investigações em psicologia tem sido destacada por diferentes autores, em diferentes épocas, e a abordagem sociocultural representa uma fonte conceitual proveitosa neste sentido. Este artigo tem como objetivo apresentar e discutir algumas idéias centrais da abordagem sociocultural, mudanças pelas quais esta abordagem passou nas últimas décadas, algumas de suas vertentes e autores. Os conceitos aqui discutidos não esgotam o tema, mas podem ser úteis para tentativas de articular investigações de diferentes temas em psicologia à abordagem sociocultural. As considerações finais apontam no sentido da necessidade de incluir as investigações em psicologia em um cenário conceitual que considere a cultura e o contexto social como elementos centrais, articulando as contribuições da psicologia transcultural e da cultura.
\end{abstract}

Palavras-chave: abordagem sociocultural, psicologia da cultura, psicologia transcultural.

\section{SOCIOCULTURAL APPROACH: SOME PERSPECTIVES AND AUTHORS}

\begin{abstract}
The need to approach sociocultural aspects in psychological investigations has been emphasized by different authors in different times, and the sociocultural approach represents a profitable conceptual source in this sense. The purpose of this article was to discuss some concepts of the sociocultural approach, changes by which this approach went through last decades, some of their perspectives and authors. The concepts here discussed can be useful in the attempts to articulate psychological investigations in a sociocultural approach. The conclusions point to the need of including the investigations in psychology into a conceptual approach that considers the culture and the social context as central elements, articulating the contributions of the cross-cultural psychology, and of the culture.
\end{abstract}

Key words: Sociocultural approach, cultural psychology, cross-cultural psychology.

A necessidade de enfocar aspectos socioculturais nas investigações em psicologia tem sido destacada por diferentes autores, em diferentes épocas, e a abordagem sociocultural representa uma fonte conceitual que parece proveitosa neste sentido. Como o próprio nome indica, ela não constitui exatamente um sistema teórico em psicologia, mas resulta da contribuição de diferentes autores, conceitos e modelos. Este artigo tem como objetivo discutir algumas idéias centrais da abordagem sociocultural, mudanças pelas quais ela passou nas últimas décadas, algumas de suas vertentes e autores.

Cabe discutir inicialmente a própria terminologia. Autores como Wertsch (1995) e Wertsch, Del Rio e
Alvarez (1998) utilizam especificamente o termo sociocultural. Outros, entretanto, como Shweder (1995) e Cole (1995; 1998), têm discutido e se referido a uma psicologia da cultura. Cole (1998) sugere, ainda, que se empregue o termo psicologia sócio-histórico-cultural para se referir a este esforço, porque considera de fundamental importância a visão de transformação histórica trazida por Vygotsky. Wertsch, Del Rio e Alvarez (1998), embora concordem com Cole em que essa é uma característica fundamental da contribuição de Vygotsky, argumentam que o termo sociocultural é mais adequado quando se trata da perspectiva contemporânea, que se apropriou das idéias desse

* Psicóloga, Doutora em Psicologia Social pela Universidade do Estado do Rio de Janeiro. Professora da Universidade Estácio de Sá. É pesquisadora integrante do grupo de pesquisa interação social e desenvolvimento, da UERJ. Coordenadora do Laboratório de Pesquisa em Psicologia Social, Akxe, Universidade Estácio de Sá.

\# Psicóloga, Doutora em Psicologia Cognitiva pela Fundação Getúlio Vargas, Livre-docente pela Universidade Federal do Rio de Janeiro. É pesquisadora IB do CNPq. Professora titular da Universidade do Estado do Rio de Janeiro, atuando no Programa de Pós-graduação em Psicologia Social do Instituto de Psicologia. 
autor. Essa é a perspectiva assumida neste trabalho, que, por essa razão, adota a terminologia sociocultural em seu título.

Esta abordagem está centrada no estudo do desenvolvimento humano enquanto um processo que se dá nas interações sociais e foi bastante influenciada pelas contribuições de L. S. Vygotsky (1896-1934). Esse autor propõe uma visão do desenvolvimento humano que destaca o seu caráter inseparável das atividades sociais e culturais.

Algumas idéias centrais caracterizam a abordagem sociocultural, destacando-se que tais idéias estão presentes, em sua origem, nas formulações teóricas de L. S. Vygotsky (1987, 1991). Segundo Rogoff e Chavajay (1995), podem-se citar alguns princípios desta abordagem, tais como: a escolha da atividade como unidade de análise, o conceito de mediação, a consideração de diferentes planos de análise, a pluralidade metodológica e a noção de que a própria atividade de pesquisa é uma construção social.

A escolha da atividade como unidade de análise dos processos psicológicos se justifica na medida em que o conceito de atividade focaliza as pessoas e o ambiente no qual elas estão inseridas (Rogoff \& Chavajay, 1995; Rogoff \& Morelli, 1989); ou seja, a atividade que os sujeitos realizam no mundo tem significado em um determinado contexto social e cultural. Como assinala Oliveira (1993), a ação humana quando, não incluída em um sistema cultural de atividade, fica destituída de significado. A atividade humana, nesta abordagem, é entendida como dotada de um sistema de significação que é permanentemente construído e transformado pelo próprio grupo cultural. Nas palavras de Vygotsky (1991): “A internalização das atividades socialmente enraizadas e historicamente desenvolvidas constitui o aspecto característico da psicologia humana" (p. 65).

Como a própria citação anterior - que trata do conceito de internalização - indica, vinculada à escolha da unidade de análise está a questão da origem social dos processos mentais. A atividade psicológica interna do indivíduo tem sua origem na atividade externa, nas trocas com os outros membros do grupo social, trocas que se inserem em um determinado contexto cultural.

Neste ponto cabe mencionar a análise de Rogoff e Morelli (1989) sobre a ênfase de Vygotsky nos níveis de análise institucional e interpessoal do contexto social. O nível institucional de análise seria o da história cultural do grupo, que organiza os instrumentos e as práticas nas quais se insere a atividade. O nível interpessoal de análise seria o do contexto de interação social da criança com os membros do seu grupo, levando em conta os instrumentos e as práticas construídos pelo próprio grupo.

Outro princípio geral adotado pela perspectiva sociocultural é o conceito de mediação, que é introduzido na psicologia por Vygotsky $(1987,1991)$ e recebe um papel importante em sua abordagem teórica. Esse autor destaca a natureza mediada da atividade humana e discute o uso de diferentes mediadores nesta atividade, por exemplo: os instrumentos materiais e os sistemas de signos.

A abordagem sociocultural enfatiza que a atividade humana é mediada e nela tem sido investigado o desenvolvimento humano dentro das práticas culturais dos grupos, que supõem o uso de diferentes formas de mediação. A partir desta orientação, entende-se que os mediadores instrumentos, signos, práticas culturais - são carregados de significação cultural. Importante ainda ressaltar que os mediadores são ao mesmo tempo utilizados, construídos e transformados pelo grupo cultural. Nas palavras de Vygotsky (1991): “a alteração provocada pelo homem sobre a natureza altera a própria natureza do homem" (p. 62).

Segundo Rogoff e Chavajay (1995), outro aspecto enfatizado pela abordagem sociocultural é o de que a investigação do desenvolvimento humano deve considerar a inter-relação entre as dimensões individual, social e cultural. O desenvolvimento é pensado como incluindo necessariamente diferentes níveis de análise: microgenético, ontogenético, sociocultural e filogenético. Ainda que um destes aspectos possa receber destaque em uma determinada investigação, é preciso levar em conta que os demais níveis estão necessariamente imbricados. Por exemplo, ao se analisar microgeneticamente a responsividade materna em díades mãe-bebê, é preciso considerar que o processo se dá em um momento da ontogênese da mãe e do bebê (faz diferença se ele é recém-nascido ou tem seis meses), que as díades vivem em um determinado contexto cultural (em uma grande cidade ocidental, ou em uma aldeia de caçadores coletores), e são membros de uma espécie que tem uma história filogenética.

A pluralidade metodológica tem também caracterizado a abordagem sociocultural, como destacam Rogoff e Chavajay (1995) e Wassmann (1995). Este último destaca a necessidade de utilização de métodos variados, como entrevistas, observações naturalísticas, experimentos em pesquisas que envolvem componentes da cultura. $\mathrm{O}$ autor defende a necessidade de se integrarem as 
contribuições metodológicas da antropologia com as da psicologia cognitiva, para que se possa compreender o funcionamento cognitivo dentro de uma determinada cultura.

Destaca-se, ainda, que as questões, os objetos de estudo, os métodos e a prática da pesquisa devem ser compreendidos como cultural e historicamente contextualizados. Neste aspecto, cabe a consideração de Rogoff e Morelli (1989) sobre a questão de que os pesquisadores desta abordagem devem estar atentos à importância dos seus sistemas de crenças sobre suas teorias e suas práticas de pesquisa. Eckensberger (2002) argumenta que a própria "ciência é um modo de se atribuir sentido à realidade, e está inserida na cultura e nos processos de mudança cultural" (p. 374). Assim, não se perde de vista que os problemas destacados para investigação e as formas de abordá-los são o produto tanto do conjunto de evidências construído por estudos anteriores, como do espírito da época nas comunidades dominantes na psicologia científica contemporânea (vide também discussão em Bronfenbrenner, Kessel, Kessen \& White, 1986).

A análise de Cole (1998) sobre os princípios da abordagem histórico-cultural que constituíram a base para a construção de uma "teoria da cultura na mente" (p. 116) mostra-se convergente com a análise de Rogoff e Chavajay (1995). Aquele autor considera como princípios: a mediação através de artefatos, o desenvolvimento histórico e a atividade prática.

Em síntese, pode-se dizer que o objetivo principal da abordagem sociocultural é compreender a relação entre o funcionamento mental humano e os settings culturais, institucionais e históricos, como discute Wertsch (1995).

\section{ABORDAGEM SOCIOCULTURAL: MUDANÇAS AO LONGO DAS ÚLTIMAS DÉCADAS}

Rogoff e Chavajay (1995) discutem como a busca de inclusão de aspectos socioculturais em estudos de desenvolvimento passou por mudanças de enfoque, de método e na natureza das pesquisas realizadas, desde a década de 1960 até os anos 1990. Antes e durante a década de 1970, os estudos incluíam, por exemplo, a aplicação de tarefas piagetianas e tarefas de memória a pessoas escolarizadas e não escolarizadas de diferentes regiões do mundo. Buscavam compreender diferenças culturais no desempenho dessas tarefas e, no primeiro caso, verificar a universalidade dos estágios hipotetizados por Piaget. Os resultados apontaram que a generalidade das tarefas era grande e que o desempenho delas não se relacionava com o que as pessoas eram capazes de fazer no cotidiano. Levaram também à conclusão de que a principal fonte de influência no desempenho das tarefas era a escolaridade.

Na década de 1980, as críticas que emergiram referiam-se à questão de poderem as mesmas tarefas ser aplicadas a pessoas de diferentes culturas. A questão da familiaridade dos materiais e das palavras utilizados nos testes foi levantada, assim como da própria natureza das tarefas que podiam não fazer sentido para determinados grupos culturais. As variações nas interpretações dos problemas e as diferenças nos métodos próprios de cada grupo para resolver as tarefas não eram consideradas. Estes aspectos colocavam em questionamento os resultados e as conclusões das pesquisas.

Tal posicionamento crítico ganha força e, como alternativa, os pesquisadores propõem considerar as tarefas como dependentes do contexto. Para isto, dedicaram-se a investigar as atividades que as pessoas realizam em suas próprias culturas e de que modo se relacionam com o que se pretende avaliar. Assim, as pesquisas na abordagem sociocultural passam a utilizar em suas investigações tarefas construídas de acordo com o contexto dos diferentes grupos culturais testados.

Rogoff e Chavajay (1995) argumentam, então, que as idéias de Vygotsky serviram como inspiração para os questionamentos da década de 1980 e embasaram a concepção de cultura e cognição, entendidas como componentes indissociáveis de um processo cuja investigação deve ser, portanto, necessariamente contextualizada.

Na década de 1990, ainda de acordo com Rogoff e Chavajay (1995), as investigações sobre cultura e cognição realizadas pela abordagem sociocultural tornaram-se significativamente interdisciplinares. As contribuições de pesquisadores e teóricos de diferentes áreas, tais como a antropologia, a sociologia e a educação, tornaram-se centrais para o desenvolvimento teórico e metodológico da abordagem sociocultural. Os autores consideram que tais esforços interdisciplinares e linhas de pesquisa de diferentes autores (p.ex. Bronfenbrenner, 1986; Cole, 1995) consolidaram, na década de 1990, um programa consistente de pesquisa sociocultural histórica, progressivamente mais coerente.

Como bem apontam Rogoff e Chavajay (1995), não se poderia apresentar uma visão totalmente homogênea do rumo que a psicologia sociocultural tomou ao longo dessas décadas. Apesar de as transformações ocorridas nos últimos quarenta anos serem, em geral, na direção destacada por estes autores, há ainda significativos desacordos em relação 
a algumas idéias centrais nesta abordagem, que se relacionam principalmente a pressupostos da psicologia transcultural e da cultura, como será discutido a seguir.

\section{ABORDAGEM SOCIOCULTURAL: AS VERTENTES DA PSICOLOGIA DA CULTURA E DA PSICOLOGIA TRANSCULTURAL}

Diferentes enfoques são apresentados pela psicologia da cultura e pela psicologia transcultural. Algumas diferenças básicas entre estas vertentes podem ser discutidas. Cabe ressaltar, entretanto, que em cada uma delas há, ainda, variações internas de orientação. Na psicologia transcultural, por exemplo, Segall, Lonner e Berry (1998) diferenciam três orientações distintas. Na psicologia da cultura, por sua vez, Cole (1998) analisa duas vertentes diferentes.

\section{A psicologia da cultura}

Cole (1998) defende uma psicologia da cultura, que seria uma "psicologia que incorpora a cultura na mente" (p. 123), utilizando a expressão do próprio autor. Esta não se constitui em uma nova disciplina ou uma subdisciplina da psicologia, mas em uma psicologia que trata a cultura como um aspecto central. As principais características da psicologia da cultura seriam, segundo Cole (1998), a ênfase na ação mediada no contexto e a concepção de que a mente emerge na atividade mediada conjunta das pessoas. Os indivíduos são considerados como agentes ativos no seu próprio desenvolvimento, mas a forma como agem nos diferentes settings depende da organização cultural.

Cole (1998) destaca que, embora haja formulações diferentes dentro da psicologia da cultura, todas elas enfatizam que o contexto sociocultural é uma parte integrante do funcionamento mental. Esse autor considera basicamente duas vertentes da psicologia da cultura, uma advinda da psicologia russa (representada por Vygotsky, Luria e Leontiev) e outra oriunda da antropologia e de teorias da cultura americanas, a qual raramente menciona o trabalho do autor russo.

Ao analisar as duas vertentes, Cole (1998) apresenta as idéias de dois autores (Shweder \& Bruner) relacionados a cada uma das vertentes. Shweder (1995) representaria a vertente da antropologia e teorias da cultura americanas, focalizando o contexto, a especificidade do conteúdo do pensamento humano e a mediação por símbolos. Bruner (1997) representaria a vertente influenciada marcadamente pela escola russa, enfatizando a emergência e funcionamento dos processos psicológicos dentro dos encontros mediados, organizados culturalmente. A ênfase se centra no chamado aspecto social-simbólico, e um de seus principais autores é o próprio Cole (1995, 1998, 2002).

A concepção de cultura descrita por Cole (1995, 1998) baseia-se fundamentalmente na noção de artefatos, ou melhor, na idéia de que os seres humanos se diferenciam porque vivem em um ambiente transformado pelos artefatos acumulados historicamente através das gerações anteriores. Conceitos como níveis de artefatos, modelos culturais, scripts, processo de mediação, são utilizados ao tratar a psicologia, ou os processos psicológicos, nas suas formas culturalmente organizadas. Nas palavras de Cole (1998):

Para que se considere o pensamento
culturalmente mediado é necessário
especificar não apenas os artefatos através
dos quais o comportamento é mediado, mas
também as circunstâncias nas quais o
pensamento ocorre. Estas considerações nos
levam de volta ao ponto essencial de que todo
comportamento humano deve ser entendido
relacionalmente, em relação ao seu contexto.
(p. 131)

Este aspecto "relacional" destacado por Cole (1998) está presente também na discussão de Jahoda (1995), em que este autor afirma que uma das idéias centrais da psicologia da cultura é a da diversidade do comportamento humano e a ligação entre o comportamento individual e o contexto cultural no qual ele ocorre.

A diversidade citada anteriormente por Jahoda (1995) remete à questão das variações e similaridades apontada por Rogoff e Chavajay (1995). Segundo estes autores, os processos de desenvolvimento são considerados na abordagem sociocultural como se se constituíssem e "ganhassem" sentido dentro de diferentes grupos culturais. Estariam tais processos, deste modo, sujeitos a aspectos comuns e a variações. Os achados de investigações a partir do enfoque sociocultural não seriam, portanto, interpretados ou analisados em termos de generalidade (por ex. generalidade entre grupos, entre indivíduos pertencentes a grupos), mas em termos de sua significação em diferentes ecologias de desenvolvimento. 
Um aspecto central para a caracterização da psicologia da cultura e para sua diferenciação relativamenteà psicologia transcultural é a definição de cultura que diferentes autores têm considerado. Segall, Lonner e Berry (1998) e Cole (1998) analisam a variedade de formas pelas quais este conceito pode ser definido. Atribui-se à psicologia da cultura uma definição de cultura como construída, criada através de interações dos indivíduos com o ambiente. Esta perspectiva enfatiza a característica construtiva da cultura, colocando-a não fora dos indivíduos, como algo que pode influenciar o comportamento, mas como uma realidade intersubjetiva.

\section{A psicologia transcultural}

Berry e Dasen (1974) apresentam três metas para a psicologia transcultural: o transporte de hipóteses para ambientes culturais diversos para testar sua validade, a exploração de variações culturais e a construção de conhecimento sobre processos universais. Com essas metas, a psicologia transcultural tem também procurado entender culturas como diferentes contextos para o desenvolvimento e discutir os comportamentos e práticas inseridos nestes contextos (Dasen \& Mishra, 2000).

Dentro dessa tendência geral, diferentes orientações podem ser observadas, e são descritas por Segall, Lonner e Berry (1998) como as de absolutismo, relativismo e universalismo. A orientação absolutista considera os fenômenos humanos como sendo basicamente os mesmos em todas as culturas. A cultura, neste enfoque, desempenharia um papel irrelevante na investigação psicológica. A orientação relativista, ao contrário, mostra pouco interesse pelas similaridades encontradas entre diferentes grupos e critica duramente comparações transculturais de caráter etnocêntrico. Por fim, a orientação universalista assume que há características comuns à espécie, e que a cultura influencia o desenvolvimento e a forma como tais características se explicitam.

Entretanto, como bem destacam Segall, Lonner e Berry (1998), apesar do acordo para as orientações relativista e universalista de que a cultura é um componente indispensável para a compreensão do comportamento humano, tem havido debate sobre diferenças conceituais em termos das formas pelas quais a cultura e o comportamento se inter-relacionam.

Esses autores (Segall, Lonner, \& Berry, 1998) apresentam como tarefa da psicologia transcultural algo muito semelhante ao anteriormente descrito em Cole (1998), ao definir a intenção da psicologia da cultura. De acordo com estes autores, a tarefa da psicologia transcultural seria a de considerar a cultura e tudo o que ela implica em relação ao desenvolvimento e comportamento como central, não periférico, na teoria e pesquisa psicológica.

A concepção de cultura que orienta a maior parte das pesquisas comparativas da psicologia transcultural é de um conjunto de variáveis contextuais que afetam o comportamento individual, algo fora dos indivíduos e basicamente entendido como um modo de vida compartilhado entre pessoas que interagem, e se transmitiria por processos de aculturação e socialização.

Essa concepção tem sido criticada pelos autores da psicologia da cultura. Segall, Lonner e Berry (1998) comentam ainda que, muitas vezes, cultura é utilizada como um rótulo para grupos (por ex. grupos de diferentes nacionalidades, grupos étnicos) ou para variáveis contextuais (por ex. políticas, históricas) nas pesquisas comparativas. Para citar apenas um exemplo, recentemente alguns pesquisadores têm mostrado interesse na discussão sobre individualismo versus coletivismo como característica da cultura e têm predito diferenças comportamentais entre grupos de diferentes nações em função destas dimensões de individualismo e coletivismo (p.ex. Triandis, Bontempo, Vilareal, Asai, \& Lucca, 1988).

Pode-se considerar, Não obstante que algumas críticas são feitas sem levar em conta a heterogeneidade do próprio enfoque e, portanto, nem sempre são pertinentes. Além disso, alguns questionamentos, como os que foram feitos na década de 1970, sobre a utilização de tarefas desvinculadas do contexto, nem sempre são aplicáveis à psicologia transcultural contemporânea.

\section{A PERSPECTIVA SOCIOCULTURAL ARTICULANDO AS DUAS TENDÊNCIAS: TRANSCULTURAL E DA CULTURA}

Independentemente das questões e das possíveis divergências entre concepções, todas as vertentes dentro da abordagem sociocultural citadas anteriormente têm trazido contribuições relevantes para a teoria e pesquisa psicológicas situadas no "contexto". A consideração feita por Segall, Lonner e Berry (1998) indica um futuro em que estas discussões sobre a psicologia da cultura e a psicologia transcultural estarão superadas. Os autores dizem: "quando toda a psicologia finalmente considerar os efeitos da cultura sobre o comportamento humano (e vice versa), termos como psicologia transcultural se tornarão desnecessários" (p. 1101).

Concordando com Segall, Lonner e Berry (1998), assume-se nesse trabalho a mesma posição de Dasen e 
Mishra (2000). Esses autores examinaram as duas posições e propõem que não são incompatíveis e que uma abordagem que incorpore o melhor das duas pode ser buscada. Apontam a necessidade de articular diferentes conceitos da abordagem sociocultural quando comentam os desenvolvimentos futuros necessários para uma visão do desenvolvimento humano que inclua a cultura.

Isso parece possível se os princípios da abordagem sociocultural acima enunciados forem levados em conta, e for empreendido um esforço de integração não só "intradisciplinar" mas também multidisciplinar. Como aponta Wertsch (1995), o objetivo de impulsionar uma abordagem sociocultural na psicologia só se cumprirá na medida em que esta for entendida como uma ciência interdisciplinar, e que, por isso, necessita da integração de idéias e métodos de diferentes disciplinas, como a psicologia, a antropologia, a sociologia, a lingüística e a história.

A necessidade de busca de interdisciplinaridade é também apontada por Valsiner (1995) e Wassmann (1995). Este último destaca a necessidade do trabalho interdisciplinar nas investigações que tenham como objetivo entender processos humanos que se constituem na cultura. Defende a integração de diferentes disciplinas, tais como a psicologia, a antropologia e a lingüística, argumentando que isoladamente estas áreas de investigação tendem a produzir resultados mais restritos, e que, por isso, não cumpririam exatamente seu objetivo.

Essa é também a posição de Sternberg e Grigorenko (2001), que defendem a necessidade de unificação de diferentes teorias em psicologia e de integração de diferentes níveis de análise (p.ex. biológico, individual, social) para que se possa investigar o desenvolvimento humano de forma mais completa.

Como exemplo dessa possibilidade de articulação proposta aqui, observa-se que um dos autores mais comumente citados como representante da abordagem transcultural, Pierre Dasen, parece assumir uma posição muito similar às considerações sugeridas pela psicologia da cultura. Isso pode ser verificado no trabalho interdisciplinar realizado por esse autor em colaboração com Wassmann (descrito por Wassmann, 1995, e mencionado anteriormente), que representa uma análise minuciosa da cultura Yupno para estudar seu funcionamento cognitivo. Os métodos utilizados em nada se assemelham às pesquisas da década de 1970, com aplicações de tarefas pouco adaptadas às culturas estudadas.
Para Valsiner (1995), a partir de 1990, especialmente, muitos esforços de incluir a cultura como parte integrante da psicologia têm emergido de diversas fontes (por ex. psicólogos transculturais, psicólogos da cultura). Tais esforços têm sido conduzidos por pesquisadores de diferentes origens e influências. Pelo fato de a abordagem sociocultural incluir esse conjunto de contribuições de diferentes autores, a apresentação dos modelos por eles propostos e de alguns dos conceitos por eles tratados pode ser relevante e é feita a seguir.

\section{ABORDAGEM SOCIOCULTURAL: AS CONTRIBUIÇÕES DE ALGUNS AUTORES}

Como já mencionado acima, há uma variedade de formas pelas quais a cultura, ou elementos da cultura (p.ex. contextos, settings, práticas culturais) têm sido incluídos, por diferentes autores e com diferentes enfoques, na psicologia. As contribuições de alguns autores neste sentido serão consideradas a seguir. Como exemplos citem-se o modelo ecológico de Bronfenbrenner (1986; 1979/1996), o enfoque de Cole (1995 e 1998) na psicologia da cultura, a noção de nicho de desenvolvimento de Harkness e Super (1994), o conceito de etnoteorias parentais (Harkness \& Super, 1992), a idéia de teorias nativas de sucesso (Ogbu, 1981), o modelo ecocultural apresentado por Berry (1995) e as contribuições de Triandis e cols. (1988), na vertente da psicologia transcultural. De modo geral, todos estes autores têm tentado compreender as ligações entre o contexto ecológico e cultural e o desenvolvimento e comportamento humanos.

Bronfenbrenner (1979/1996) propõe um modelo explicativo para o desenvolvimento humano que leva em conta o contexto social amplo no qual o indivíduo está inserido. A análise do contexto social, para ese autor, não pode se limitar a um aspecto, ao contrário, deve considerar vários aspectos.

O modelo ecológico - como é chamada a formulação de Bronfenbrenner - aponta para a necessidade de descrição e análise sistemáticas dos contextos, das interconexões entre eles e dos processos através dos quais eles podem afetar o desenvolvimento. A influência de Lewin (1973) sobre este modelo, descrita em Bronfenbrenner (1979/1996) e em Rogoff e Chavajay (1995), reforça a idéia de que é preciso, ao estudar o comportamento e desenvolvimento humanos, levar em conta não só a situação imediata na qual o indivíduo está, mas também os diferentes sistemas que envolvem o indivíduo: microssistema, mesossistema, exossistema e macrossistema. 
O conhecimento destes sistemas permite diferenciar as propriedades ecológicas dos contextos de desenvolvimento humano, na medida em que eles tratam de esferas ou dimensões variadas que envolvem o sujeito. $\mathrm{O}$ microssistema inclui as atividades, papéis e relações interpessoais que se dão entre as pessoas em um determinado ambiente físico e material. $\mathrm{O}$ mesossistema inclui as relações entre dois ou mais ambientes nos quais a pessoa em desenvolvimento participa ativamente (tais como as relações em casa, na escola, no trabalho). Os mesossistemas são continuamente modificados sempre que a pessoa começa a participar de um novo ambiente. Já os exossistemas são aqueles ambientes dos quais a pessoa não participa diretamente, mas nos quais ocorrem eventos significativos que a afetam. Por exemplo, para uma criança, seriam exossistemas o local de trabalho dos pais, a rede de amigos dos pais. Os macrossistemas seriam as diferentes culturas (p.ex. os sistemas de crenças, as ideologias, as formas e conteúdos das relações interpessoais) que envolvem todos os outros sistemas.

Como assinalam Collins, Maccoby, Steinberg e Bornstein (2000), o modelo ecológico serve como base para investigações sobre o desenvolvimento integradas a diferentes esferas do contexto social (p.ex. as relações em casa, a vizinhança, o contexto cultural, aépoca histórica). Neste sentido, pode-se dizer que o modelo de Bronfenbrenner converge com o conceito de nichos de desenvolvimento proposto por Harkness e Super (1994). Segundo estes autores, as investigações sobre o processo de desenvolvimento humano devem considerar a criança e o ambiente como um sistema interativo. $\mathrm{O}$ nicho de desenvolvimento envolve três subsistemas: o ambiente físico e social da criança; os costumes culturalmente construídos sobre os cuidados e modos de criar as crianças e a psicologia dos que cuidam das crianças.

No subsistema do ambiente físico e social estão as fontes mais diretas de informação sobre como o ambiente social da criança é estruturado. Pode-se observar como, onde, em que condições materiais, com quem a criança vive, quais são as figuras de cuidado. Os costumes e os modos de cuidar das crianças constituem outro subsistema, que, neste caso, informa sobre as práticas comuns de cada grupo ao criar e cuidar das crianças. A psicologia dos cuidadores seria o terceiro subsistema, o qual trata das crenças e expectativas daqueles que cuidam das crianças.

Com o conceito de etnoteorias parentais, Harkness e Super (1992) exploram mais detalhadamente este terceiro componente dos nichos de desenvolvimento, que é o das representações que os pais têm sobre o desenvolvimento infantil, suas expectativas, crenças e quanto eles regulam suas ações, suas práticas de cuidado e educação, tendo como base suas representações. Ogbu (1981) já havia também destacado este ponto ao traçar as relações entre diferentes componentes dos sistemas de cuidado. Esse autor trata, entre outros aspectos, das chamadas teorias nativas de sucesso, nas quais os pais se baseiam para orientar a criação de seus filhos. Este aspecto é ainda destacado por Small (1999) ao discutir como as práticas de cuidado ganham sentido dentro de cada grupo social e quanto tais práticas são delineadas para produzir o tipo de "cidadão" esperado ou desejável em cada cultura. Os pais, certamente, enquanto membros do grupo cultural, exercem seus cuidados e educação das crianças de modo a alcançar as metas desejáveis.

O conceito de nicho de desenvolvimento (Harkness \& Super, 1994), como os próprios autores afirmam, derivou de estudos de campo sobre desenvolvimento infantil e condições de vida, aspectos da vida familiar, em diferentes contextos culturais (p.ex.Quênia e Estados Unidos). O desenvolvimento deste conceito teve, segundo Harkness e Super (1994), importantes contribuições, podendo ser destacadas as seguintes: a contribuição de Bronfenbrenner, ao apresentar o modelo ecológico e enfatizar o estudo do desenvolvimento humano no contexto; a colaboração muito frutífera entre a psicologia e a antropologia ao introduzir novas formas de investigar a diversidade do desenvolvimento; e as perspectivas de ciclo de vida, que também emergiram nesta época, dando ênfase aos aspectos contínuos dos ambientes "psicológicos" que caracterizam o desenvolvimento humano.

Pode-se afirmar que, tanto na concepção de Bronfenbrenner (1979/1996) quanto na de Harkness e Super (1994), é ressaltada a idéia de que o estudo do desenvolvimento humano deve considerar os diferentes domínios que envolvem o sujeito, desde aqueles que mostram uma relação direta, mais imediata, até os de influência indireta. Estes domínios, uma vez que fazem parte do ambiente social e cultural, estarão continuamente se transformando e "dando forma" aos processos de desenvolvimento.

Berry (1995) apresenta um modelo que procura também levar em conta diferentes níveis de análise e que se inclui na chamada abordagem transcultural. Berry (1995) ressalta que a cultura deve ser tratada como elemento-chave na psicologia e que se deve entender "culturas" como diferentes contextos para o desenvolvimento. O modelo ecocultural, como é descrito, propõe que se considere a diversidade 
psicológica humana como produto de adaptações dos indivíduos e dos grupos aos diferentes contextos. Estas adaptações seriam influenciadas basicamente por condições ecológicas e sociopolíticas.

Ainda dentro da chamada abordagem transcultural, devem-se comentar as contribuições de Triandis e cols. (1988). Estes autores enfatizam, também, o papel da cultura, entretanto centram suas investigações em níveis de análise bem mais específicos (p.ex. coletivismo). Consideram que para investigar de que forma a cultura se relaciona ao fenômeno psicológico é preciso analisar algumas dimensões da variação cultural e tentar compreender sua relação com manifestações psicológicas e sociais. Uma das dimensões de variação cultural considerada promissora para esta análise é a do individualismo versus coletivismo, supondo-se que ao nível social uma dessas dimensões seja enfatizada. Estas dimensões a nível social seriam refletidas em dimensões da personalidade (p.ex. alocentrismo e idiocentrismo).

Assumindo uma posição diferente da defendida por Triandis, por exemplo, Cole $(1995,1998)$ rejeita a idéia de causa e efeito para explicar as relações entre a cultura e aspectos psicológicos; supõe que a mente e a cultura se criam em um processo dinâmico. Cole (1998) propõe uma psicologia da cultura que traz influências marcantes da psicologia histórico-cultural russa e enfatiza os seguintes aspectos: a mediação através de artefatos, o desenvolvimento histórico e a atividade prática. Esse autor destaca a produção, acumulação e transformação histórica dos artefatos. Neste ponto, traça uma relação direta com Vygotsky (1991), ao ressaltar a natureza social dos artefatos e as origens sociais dos processos mentais humanos; mas, ao invés de tratar do conceito de instrumento como o fizeram os russos, este autor utiliza o conceito de instrumento como uma subcategoria de uma definição mais geral de artefato. A noção de instrumento é ampliada na de artefatos, já que Vygotsky (1991) originalmente tratava de duas categorias ao discutir os instrumentos (instrumentos materiais e psicológicos) e a noção de artefatos, por sua vez, inclui três níveis, como será visto a seguir.

Os artefatos são elementos mediadores da ação humana no mundo - utilizando-se as palavras do próprio autor, "constituintes fundamentais da cultura" (Cole, 1998, p.145). São construídos e transformados historicamente e se mostram em três níveis diferenciados. Cole (1998) distingue os artefatos primários, que seriam os instrumentos e objetos materiais, os secundários, que seriam esquemas, normas sociais e, por fim, os artefatos terciários. Estes seriam representados pelos scripts, conjunto de atividades ou seqüências de ações que tendem a ser realizadas por membros do grupo cultural, de certa maneira, utilizando-se de artefatos primários (por ex.: objetos) e secundários (por ex.: normas sociais). Os scripts são compartilhados interpessoalmente e orientam os membros do grupo sobre o que é esperado em diferentes situações (Cole, 1998).

Desse modo, em relação à noção de cultura, Cole (1998) não adota nem a posição de externalização, de cultura como de produtos da atividade humana, nem a de uma característica interna da mente, conjunto de crenças e conhecimentos. Os artefatos, para ele, são "aspectos do mundo material que foram modificados através da história de sua incorporação em ações humanas dirigidas a metas" (p.117). São, ao mesmo tempo, ideais e materiais. Artefatos e atividades estão imbricados entre si e com o mundo social dos seres humanos em que são mediadores, formando redes e estruturas organizadoras (esquemas, scripts, modelos culturais). Essas redes e organizações constituem a cultura. Assim, esse autor pensa que tomou o caminho do meio.

Artefatos são criados e usados em atividades sociais. Segundo Cole (1998), para estudar comportamento humano e seu desenvolvimento, é necessário estudar o contexto em que ocorrem, em termos dos artefatos e sua organização, mas, ao mesmo tempo, incorporar os resultados da pesquisa sobre processos delimitados filogeneticamente.

Os artefatos são produzidos pelo próprio grupo, dentro da cultura, e ganham sentido naquele contexto. Assim, Cole (1998) ressalta que é preciso conhecer não somente os objetos mediadores da ação, mas as circunstâncias nas quais as ações ocorrem. Volta-se, neste ponto, para a idéia destacada anteriormente, sobre a posição relacional identificada na contribuição deste autor e também de Jahoda (1995).

Em síntese, diversos autores têm contribuído de modo muito significativo tanto para as discussões teóricas sobre a abordagem sociocultural, quanto para o desenvolvimento de investigações em psicologia que levem em conta a cultura e os contextos sociais.

\section{CONSIDERAÇÕES FINAIS}

Parece consensual a constatação de que, nos últimos anos, houve um incremento nas publicações de livros e artigos em periódicos que levam em conta a cultura (Valsiner, 1995), considerando diferentes concepções dentro da abordagem sociocultural. Entretanto, seguindo o argumento de Wertsch (1995), pode-se afirmar que, embora a necessidade de integrar 
a psicologia em análises mais amplas, envolvendo a cultura e as condições sociais, esteja sendo amplamente discutida, a tradução desta idéia para a prática tem sido mais difícil.

Um dos inúmeros desafios para os pesquisadores em psicologia parece ser o de incluir suas investigações em um cenário conceitual que considere a cultura e o contexto social como elementos centrais. Por um lado, pode-se, com isto, conhecer um pouco melhor a diversidade de práticas, costumes, comportamentos, representações, crenças etc. Por outro lado, pode-se também avançar em desenvolvimentos teóricos ou conceituais mais flexíveis em psicologia, que dêem conta de compreender essa diversidade de modo mais satisfatório.

Certamente as perspectivas e tendências aqui discutidas não esgotam o tema, mas entende-se que podem servir como um pano de fundo útil para tentativas de levar a cultura a sério nos estudos psicológicos. Conclui-se com a convicção de que a articulação de algumas dessas tendências é não só possível, mas também desejável, e que os pressupostos da abordagem sociocultural podem servir de guia para essa busca de síntese.

\section{REFERÊNCIAS}

Berry, J. W. (1995). The descendants of a model: Comments on Jahoda (1995). Culture \& Psychology, 1(3), 373-380.

Berry, J.W. \& Dasen, P.R (Eds.). (1974). Culture and cognition: Readings in cross-cultural psychology. London: Methuen.

Bronfenbrenner, U. (1986). Ecology of the family as a context for human development: Research perspectives. Developmental Psychology, 22, 723-742.

Bronfenbrenner, U. (1996). A ecologia do desenvolvimento humano: Experimentos naturais e planejados. Porto Alegre: Artes Médicas. (Originalmente publicado em 1979)

Bronfenbrenner, U., Kessel, F., Kessen, W., \& White, S. (1986). Toward a critical social history of developmental psychology: A propaedeutic discussion. American Psychologist, 41(11), 1218-1230.

Bruner, J. (1997). Atos de significação. Porto Alegre: Artes Médicas

Cole, M. (1995). Culture and cognitive development: From cross-cultural research to creating systems of cultural mediation. Culture \& Psychology, 1, 25-54.

Cole, M. (1998). Cultural psychology: A once and future discipline. Cambridge: Harvard University Press.

Cole, M. (2002). Culture and development Em H. Keller, Y. H. Poortinga \& A. Shölmerich (Orgs.), Between culture and biology (pp. 303-319). Cambridge: Cambridge University Press.

Collins, W. A., Maccoby, E. E., Steinberg, L. \& Bornstein, M. H. (2000). Contemporary research on parenting. American Psychologist, 55, 218-232.

Dasen, P. R. \& Mishra, R. C. (2000). Cross-cultural views on human development in the third millenium. International Journal of Behavioral Development, 24, 429-434.

Eckensberger, L. H. (2002). Paradigms revisited: from incommensurability to respected complementarity. Em $\mathrm{H}$. Keller, Y. H. Poortinga \& A. Shölmerich (Orgs.), Between culture and biology (pp. 341-383). Cambridge: Cambridge University Press.

Harkness, S. \& Super, C. M. (1992). Parental ethnoteories in action. In I. E. Sigel, A. V. McGillicuddy-DeLisi \& J. J. Goodnow (Eds.), Parental belief systems: The psychological consequences for children (pp. 373-391). Hillsdale: Lawrence Erlbaum Associates Puiblishers.

Harkness, S. \& Super, C. M. (1994). Developmental niche: A theoretical framework for analyzing the household production of health. Social Science and Medicine, 38, 219-226.

Jahoda, G. (1995). The ancestry of a model. Culture \& Psychology, 1, 11-24.

Lewin, K. (1973). Princípios de psicologia topológica. São Paulo: Cultrix.

Ogbu, J. (1981). Origins of human competence: A culturalecological perspective. Child Development, 52, 413-429.

Oliveira, M. K. (1993). Vygotsky, aprendizado $e$ desenvolvimento um processo sócio-histórico. São Paulo: Scipione.

Rogoff, B. \& Chavajay, P. (1995). What's become of research on the cultural basis of cognitive development. American Psychologist, 50, 859-877.

Rogoff, B. \& Morelli, G. A. (1989). Perspectives on children's development from cultural psychology. American Psychologist, 44, 343-348.

Small, M. F. (1999). Our babies, ourselves: How biology and culture shape the way we parent. New York: Anchor Books.

Segall, M. H., Lonner, W. J. \& Berry, J. W. (1998). Crosscultural Psychology as a scholarly discipline. On the flowering of culture in behavioral research. American Psychologist, 53, 1101-1110.

Shweder, R. A. (1995). The confessions of a methodological individualist. Culture \& Psychology, 1(1), 115-122.

Sternberg, R. J. \& Grigorenko, E. L. (2001). Unified Psychology. American Psychologist, 56, 1069-1079.

Triandis, H. C., Bontempo, R., Villareal, M. J., Asai, M., \& Lucca, N. (1988). Individualism and collectivism. Crosscultural perspectives on self-ingroup relationships. Journal of Personality and Social Psychology, 54, 323-338.

Valsiner, J. (1995). Editorial culture and psychology. Culture \& Psychology, 1, 5-10.

Vygotsky, L. S. (1987). Pensamento e linguagem. São Paulo: Martins Fontes. 
Vygotsky, L. S. (1991). A formação social da mente. São Paulo: Martins Fontes.

Wassmann, J. (1995). The final requiem for the omniscient informant? An interdisciplinary approach to everyday cognition. Culture \& Psychology, 1,167-201.

Wertsch, J. V. (1995). Sociocultural research in the copyright age. Culture \& Psychology, 1, 81-102.

Wertsch, J. V., Del Rio, P., \& Alvarez, A. (1998). Estudos socioculturais: história, ação e mediação. Em J. V. Wertsch, P. Del Rio \& A. Alvarez (Orgs.), Estudos socioculturais da mente (pp. 11-38). Porto Alegre: Artes Médicas.

Endereço para correspondência: Adriana Ferreira Paes Ribas. Rua Maria Amália, 87, ap. 401, Tijuca, CEP 20510-130, Rio de Janeiro.E-mail: aribas@globo.com 